\begin{tabular}{|l|l|l|l|l|l|}
\hline J. Tek. Ling & Vol. 12 & No. 2 & Hal. $161-169$ & Jakarta, Mei 2011 & ISSN 1441-318X \\
\hline
\end{tabular}

\title{
STRUKTUR DAN KOMPOSISI VEGETASI POHON SERTA ESTIMASI BIOMASSA, KANDUNGAN KARBON DAN LAJU FOTOSINTESIS DI TAMAN NASIONAL GUNUNG HALIMUN-SALAK
}

\author{
Muhammad Mansur, Nuril Hidayati dan Titi Juhaeti \\ Bidang Botani, Puslit Biologi-LIPI \\ Cibinong Science Center, Jl. Raya Jakarta-Bogor, Km.46, Cibinong \\ E-mail: mansurhalik@yahoo.com
}

\begin{abstract}
Research the structure and composition of vegetation, biomass estimation, carbon content and the rate of photosynthesis was conducted in Citalahab Central Village, Gunung Halimun-Salak National Park, West Java, on August 2010. The purpose of research to determine the components and characteristics of each tree species at the study sites associated with biomass, the rate of $\mathrm{CO}_{2}$ assimilation and transpiration. Results showed that, the form of classified forest area of primary forest with a little disturbed. There were recorded 337 individual trees (stem diameter $>10 \mathrm{~cm}$ ) per hectare from 71 species, 50 genera and 32 families. Lauraceae, Fagaceae, Myrtaceae, Rubiaceae and Meliaceae are the 5 most common families found in the plot area, that is dominated by Altingia excelsa, Blumeodendron elateriospermum, Ardisia zollingeri, Gordonia excelsa, Tricalysia singularis, Castanopsis acuminatissima, Knema cinerea, Laportea stimulant, Vernonia arborea and Dysoxylum excelsum. Estimated biomass recorded of 304.5 tons dry weight / ha with a carbon content of 152.3 tons / ha of basal area of $28.89 \mathrm{~m}^{2} / \mathrm{ha}$. Quercus oidocarpa, Litsea noronhae, Saurauia nudiflora, Castanopsis argentea and Altingia excelsa has recorded the highest photosynthetic rates compared with other species. While the highest transpiration rate is owned by the Macaranga triloba, Sandoricum koetjape, Prunus arborea, Urophyllum corymbosum and Altingia excelsa.
\end{abstract}

Key words: Structure, Composition, Biomass, Photosynthesis, Transpiration, Vegetation, Halimun-Salak National Park.

\section{PENDAHULUAN}

\subsection{Latar Belakang}

Taman Nasional Gunung Halimun (TNGH) adalah salah satu kawasan konservasi hutan pegunungan terluas di Jawa Barat, kawasan ini ditetapkan sebagai Taman Nasional dengan SK Menteri Kehutanan No.282/kpts-II/1992 dengan luas areal 40.000 ha. Namun dengan adanya penggabungan TNGH dengan kawasan Gunung Salak pada tanggal 10 Juni 2003 dengan keluarnya SK Menteri Kehutanan No. 175/kpts-II/2003, maka luasnya bertambah menjadi 113.357 ha dan diberi nama Taman Nasional Gunung Halimun-Salak (TNGHS) ${ }^{1}$.

Tahun-tahun sebelumnya sudah 
banyak penelitian yang dilakukan oleh Pusat Penelitian Biologi-LIPI bekerjasama dengan Departemen Kehutanan khususnya TNGHS dan Pemerintah Jepang (JICA), baik itu yang berkaitan dengan tumbuhan, hewan, maupun jasad renik. Namun demikian penelitian tumbuhan yang berkaitan dengan Ekofisiologi belum dilakukan, khususnya mengenai karakteristik pohon, kandungan karbon dan laju fotosintetiknya.

Hutan menduduki $21 \%$ dari daratan, $76 \%$ dari total biomasa terestrial. Jadi vegetasi dalam hutan memiliki bagian yang esensial dari fungsi biosfer terestrial, terutama dalam siklus karbon. Walaupun demikian fotosintesis tumbuhan di hutan masih sangat sedikit dipelajari dibandingkan fotosintesis tanaman pertanian karena beberapa kendala, diantaranya ukuran dari pohon dewasa yang terlalu besar, menyebabkan pengukuran sulit dilakukan, jumlah spesies yang terlampau banyak dan sulitnya mengukur fotosintesis dari keseluruhan pohon pada seluruh wilayah hutan ${ }^{2)}$. Laju Asimilasi $\mathrm{CO}_{2}$ sangat beragam di antara jenis pohon, tidak hanya di daerah empat musim tetapi juga di daerah tropis. Jenis-jenis tumbuh cepat kerap memiliki laju asimilasi $\mathrm{CO}_{2}$ yang relatif lebih tinggi ${ }^{3}$.

Kapasitas fotosintesis, yakni kapasitas potensial dari tumbuhan dalam berfotosintesis pada kondisi lingkungan yang optimum, dapat dijadikan sebagai parameter untuk menunjukkan seberapa baik suatu tanaman tumbuh pada suatu kondisi lingkungan tertentu. Dengan membandingkan kapasitas fotosintesis dari jenis-jenis tumbuhan pada berbagai tipe vegetasi pada kondisi lingkungan yang berbeda dapat mencerminkan kesesuaian dari lingkungan bagi jenis tumbuhan tersebut $4,5)$.

Dalam penelitian ini dilakukan analisis dan evaluasi terhadap parameter-parameter ekologis (nilai dominan, nilai penting, luas bidang dasar, biomasa dan kandungan karbon) serta parameter-parameter fisiologis (fotosintesis, transpirasi) dari tumbuhan- tumbuhan pohon penyusun ekosistem hutan konservasi Taman Nasional Gunung Halimun-Salak.

\subsection{Tujuan Penelitian}

Tujuan dari penelitian ini adalah untuk mengetahui struktur dan komposisi vegetasi pohon yang berkaitan dengan kandungan karbon dan laju fotosintesisnya di sebagian kawasan TNGHS. Diharapkan dari hasil penelitian ini dapat diketahui jenis-jenis pohon dominan serta mendapatkan informasi data tentang kandungan karbon pada pohon dan laju fotosintesisnya untuk pemilihan jenis dalam usaha reboisasi hutan, sehingga emisi $\mathrm{CO}_{2}$ di udara yang merupakan penyebab utama dari terjadinya pemanasan global dapat ditekan.

\section{METODOLOGI}

Penelitian dilakukan pada bulan Agustus 2009, di dalam kawasan Taman Nasional Gunung Halimun-Salak. Plot seluas 1 hektar $(100 \times 100 \mathrm{~m})$ pada kawasan terpilih dibuat dengan metoda petak kuadrat yang dibagi menjadi 100 subplot dengan ukuran masing-masing $10 \times 10 \mathrm{~m}$. Seluruh jenis pohon (diameter batang $>10 \mathrm{~cm}$ ) di dalam subplot dicatat, antara lain; nama jenis, jumlah pohon, diameter batang, tinggi pohon, dan posisi pohon (koordinat $\mathrm{x}$ dan $y)$. Parameter tersebut untuk mengetahui persebaran, stratifikasi dan kelimpahan masing-masing jenis.

Seluruh data yang terkumpul dianalisis dengan cara Cox ${ }^{6}$ dan Greigh-Smith ${ }^{7)}$ untuk mendapatkan nilai Luas Bidang Dasar (LBD), Frekuensi Relatif (FR), Kerapatan Relatif (KR), Dominansi Relatif (DR) dan Nilai Penting (NP). Nilai LBD didapat dari hasil perhitungan rumus:

$$
\operatorname{LBD}=(0,5 \times D)^{2} \times 3,14
$$

Dimana $\mathrm{D}$ adalah diameter batang dan nilai 3,14 adalah konstanta. Sedangkan 
untuk menghitung Estimasi biomassa dan kandungan karbon digunakan rumus Brown ${ }^{8)}$, sbb;

$$
\mathbf{W}=\mathbf{a} \mathbf{D}^{\mathbf{b}}
$$

Dimana W adalah Biomassa, D diameter batang, a dan b adalah konstanta sebesar 0,19 dan 2,37. Penghitungan karbon menggunakan rumus sbb;

$$
C=0,5 \mathrm{~W}
$$

Dimana C adalah kandungan karbon dan $\mathrm{W}$ adalah biomassa.

Pengukuran laju asimilasi CO2 dan laju transpirasi, dilakukan pada anak pohon (tinggi dibawah $3 \mathrm{~m}$ ), baik yang ada di dalam plot maupun di luar plot dengan menggunakan alat ADC LCI portabel Bioscientific. Pengukuran iklim mikro dilakukan pada setiap jenis tumbuhan yang diukur, antara lain adalah; Suhu udara dan kelembaban udara diukur dengan menggunakan Thermohygrometer, $\mathrm{pH}$ tanah dan kelembaban tanah diukur dengan menggunakan alat soil tester dan Intensitas cahaya diukur dengan menggunakan Lux meter. Pengukuran dari masing-masing jenis, dilakukan pada waktu di antara jam 10,00-13,00 am di bawah langit cerah.

\section{HASIL DAN PEMBAHASAN}

\subsection{Keadaan Umum Lokasi}

Lokasi plot penelitian berada pada kaki gunung kendeng pada ketinggian $1076 \mathrm{~m} \mathrm{dpl}$ dan pada posisi koordinat GPS di antara 060 44' 32.2" Lintang Selatan dan 1160 31' 44.0" Bujur Timur. Lokasi plot kurang lebih $1 \mathrm{~km}$ jaraknya dari Kampung Citalahab Sentral dan secara administratif termasuk ke dalam Desa Malasari, Kecamatan Nanggung, Kabupaten Bogor (Gambar 1). Kampung tersebut dapat ditempuh 5 jam perjalanan dengan kendaraan bermotor dari Kota Bogor. Hutannya termasuk hutan primer dalam kondisi baik dengan topografi lahannya berbukit. Jenis tanahnya tergolong pada Latosol coklat kemerahan. Berdasarkan klasifikasi curah hujan tahunan, lokasi penelitian termasuk kedalam wilayah Tipe iklim A dengan curah hujan tahunan di antara 4500-5000 mm/tahun ${ }^{9)}$.

\subsection{Struktur dan Komposisi}

Dari hasil sensus seluas 1 ha, diketahui ada 337 individu pohon (diameter batang $>10 \mathrm{~cm}$ ) yang tercatat, meliputi 71 jenis dari 50 marga dan 32 suku dengan Luas Bidang Dasar (LBD) sebesar 28,894 m2/ ha. Suku yang umum ditemukan antara lain adalah; Lauraceae, Fagaceae, Myrtaceae, Rubiaceae, Meliaceae dan Euphorbiaceae.

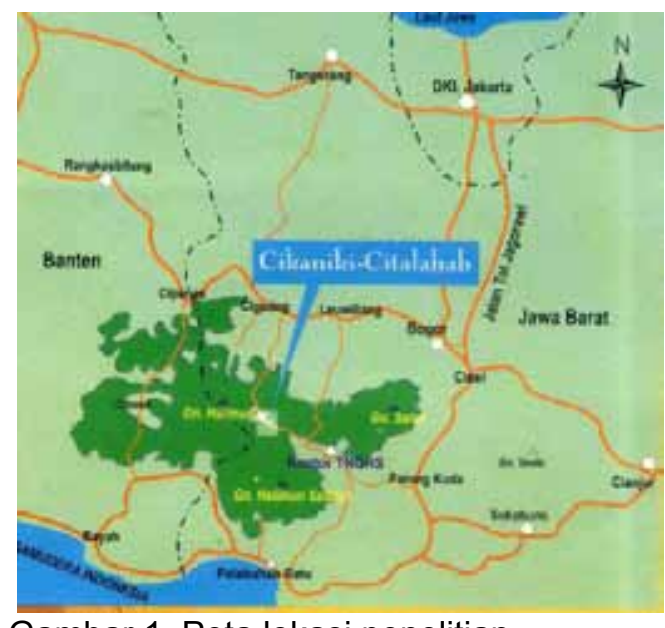

Gambar 1. Peta lokasi penelitian

Hasil analisis data tercatat ada 20 jenis pohon dominan yang memiliki Nilai Penting (NP) tertinggi, antara lain; Altingia excelsa, Blumeodendron elateriospermum, Ardisia zollingeri, Gordonia excelsa, Tricalysia singularis, Castanopsis acuminatissima, Knema cinerea, Laportea stimulans, Vernonia arborea, Dysoxylum excelsum dan 10 jenis lainnya seperti terlihat pada Tabel 1. 
Tabel 1. Dua puluh jenis pohon dominan yang tercatat di dalam plot penelitian.

\begin{tabular}{|c|l|c|c|c|c|c|}
\hline No. & Nama Latin & $\begin{array}{c}\text { LBD } \\
\left(\mathrm{m}^{2} / \mathrm{ha}\right)\end{array}$ & $\mathrm{FR}(\%)$ & $\mathrm{KR}(\%)$ & $\mathrm{DR}(\%)$ & $\mathrm{NP}(\%)$ \\
\hline 1 & Acer laurinum & 0.55 & 1.96 & 2.08 & 1.90 & 5.93 \\
\hline 2 & Altingia excelsa & 7.68 & 5.88 & 6.23 & 26.59 & 38.71 \\
\hline 3 & Ardisia zollingeri & 0.26 & 6.54 & 6.53 & 0.88 & 13.95 \\
\hline 4 & $\begin{array}{l}\text { Blumeodendron } \\
\text { elateriospermum }\end{array}$ & 2.49 & 5.88 & 6.53 & 8.62 & 21.03 \\
\hline 5 & $\begin{array}{l}\text { Castanopsis } \\
\text { acuminatissima }\end{array}$ & 1.81 & 1.63 & 3.56 & 6.26 & 11.46 \\
\hline 6 & $\begin{array}{l}\text { Castanopsis } \\
\text { argentea }\end{array}$ & 1.12 & 1.96 & 1.78 & 3.87 & 7.62 \\
\hline 7 & $\begin{array}{l}\text { Castanopsis } \\
\text { javanica }\end{array}$ & 0.72 & 1.63 & 1.48 & 2.48 & 5.60 \\
\hline 8 & Cinnamomum sp. & 0.77 & 1.96 & 1.78 & 2.66 & 6.40 \\
\hline 9 & $\begin{array}{l}\text { Dysoxyllum } \\
\text { excelsum }\end{array}$ & 1.08 & 3.59 & 3.56 & 3.73 & 10.88 \\
\hline 10 & $\begin{array}{l}\text { Elaeocarpus } \\
\text { ganitrus }\end{array}$ & 0.70 & 1.31 & 1.19 & 2.44 & 4.93 \\
\hline 11 & Gordonia excelsa & 0.54 & 5.88 & 5.93 & 1.89 & 13.70 \\
\hline 12 & Knema cinerea & 0.97 & 3.92 & 4.15 & 3.35 & 11.43 \\
\hline 13 & $\begin{array}{l}\text { Laportea } \\
\text { stimulans }\end{array}$ & 0.24 & 5.23 & 5.34 & 0.82 & 11.39 \\
\hline 14 & Litsea resinosa & 0.41 & 1.96 & 2.08 & 1.41 & 5.45 \\
\hline 15 & Litsea tomentosa & 0.20 & 2.94 & 2.67 & 0.69 & 6.30 \\
\hline 16 & Magnolia elegans & 0.97 & 3.59 & 2.97 & 3.37 & 9.93 \\
\hline 17 & $\begin{array}{l}\text { Sandoricum } \\
\text { koetjape }\end{array}$ & 0.25 & 2.61 & 2.37 & 0.85 & 5.84 \\
\hline 18 & $\begin{array}{l}\text { Tricalysia } \\
\text { singularis }\end{array}$ & 0.50 & 4.90 & 5.04 & 1.75 & 11.69 \\
\hline 19 & $\begin{array}{l}\text { Urophyllum } \\
\text { corymbosum }\end{array}$ & 0.09 & 2.61 & 2.37 & 0.32 & 5.31 \\
\hline 20 & Vernonia arborea & 1.31 & 3.27 & 3.56 & 4.53 & 11.36 \\
\hline & 50 Jenis lainnya & 6.24 & 30.72 & 28.78 & 21.60 & 81.10 \\
\hline & Jumlah & 28.89 & 100.00 & 100.00 & 100.00 & 300.00 \\
\hline
\end{tabular}

Keterangan : LBD= Luas Bidang Dasar, FR= Frekuensi Relatif, KR= Kerapatan Relatif, DR= Dominansi Relatif, NP= Nilai Penting.

\subsection{Sebaran Kelas Diameter Batang}

Sebaran kelas diameter batang pohon tertinggi tercatat pada tingkat kelas diameter di antara $10-20 \mathrm{~cm}$, yakni tercatat sebesar
$51,63 \%$ dari total individu. Jenis pohon yang umum menempati kelas diameter tersebut antara lain adalah; Ardisia zollingeri, Laportea stimulans, Gordonia excelsa dan Urophyllum glabrum. Jumlah nilai sebaran 
menurun dengan meningkatnya tingkat kelas diameter batang, seperti terlihat pada Tabel 2.

Jenis Altingia excelsa, Engelhardia serrata dan Blumeodendron elateriospermum merupakan jenis pohon yang memiliki diameter batang bisa mencapai lebih dari $100 \mathrm{~cm}$. Burununggul (Blumeodendron elateriospermum) tercatat sebagai jenis pohon yang paling tinggi tingkat persebarannya, mulai dari diameter 10 hingga lebih dari $100 \mathrm{~cm}$. Sedangkan Rasamala (Altingia excelsa) mulai dari diameter $30 \mathrm{~cm}$ hingga di atas $100 \mathrm{~cm}$. Dengan demikian jenis Blumeodendron elateriospermum dapat dikatakan memiliki kemampuan tingkat regenerasi cukup baik dibandingkan dengan jenis lainnya.

Tabel 2. Tingkat penyebaran kelas diameter batang pohon.

\begin{tabular}{|c|c|}
\hline Kelas diameter & Jumlah (\%) \\
\hline $10,0-20,0$ & 51.63 \\
\hline $20,1-30,0$ & 17.51 \\
\hline $30,1-40,0$ & 12.17 \\
\hline $40,1-50,0$ & 8.31 \\
\hline $50,1-60,0$ & 4.15 \\
\hline $60,1-70,0$ & 2.08 \\
\hline $70,1-80,0$ & 1.78 \\
\hline $80,1-90.0$ & 0.59 \\
\hline $90,1-100,0$ & 0.59 \\
\hline$>100$ & 1.19 \\
\hline Total & 100.00 \\
\hline
\end{tabular}

\subsection{Stratifikasi Tegakan Pohon}

Bentuk stratifikasi tegakan pohon terlihat ada tiga lapisan tajuk, penutupan kanopi tampak rapat pada lapisan satu (tinggi tajuk kurang dari $15 \mathrm{~m}$ ) yakni sebesar $65,3 \%$ dari jumlah total individu, kemudian diikuti lapisan kedua $(29,7 \%)$ dan lapisan ketiga (5\%). Lapisan pertama umumnya ditempati Ardisia zollingeri, Urophyllym glabrum, Laportea stimulan dan Gordonia excelsa yang tingginya rata-rata di bawah $15 \mathrm{~m}$. Sedangkan Dysoxylum excelsum, Vernonia arborea dan Huru-huruan dari suku Lauraceae menempati lapisan kedua yang tinggi pohonnya rata-rata di antara 15-30 m. Lapisan ketiga yang tinggi pohonnya di atas $30 \mathrm{~m}$ ditempati oleh Altingia excelsa, Schima wallichii dan Castanopsis acuminatisstima.

\subsection{Biomassa dan Kandungan Karbon}

Jumlah total biomassa (pohon) di atas permukaan tanah tercatat sebesar $304495,81 \mathrm{~kg}$ (304,5 ton) berat kering/ha dan kandungan karbon 152247,91 (152,3 ton/ha) dari total Luas Bidang Dasar sebesar $28,89 \mathrm{~m}^{2} /$ ha dan jumlah individu sebesar 337 pohon. Tercatat ada 5 jenis pohon yang memiliki kandungan karbon tertinggi, yakni; Altingia excelsa $(46,91$ ton/ha), Blumeodendron elateriospermum $(14,41$ ton/ha), Castanopsis acuminatissima $(9,65$ ton/ha), Engelhardia serrata (8,04 ton/ha) dan Vernonia arborea (6,86 ton/ha). Jumlah biomassa dan kandungan Karbon dari masing-masing jenis pohon dapat dilihat pada Tabel 3.

\subsection{Laju Fotosintesis dan Transpirasi}

Proses fotosintesis berkaitan dengan asimilasi $\mathrm{CO}_{2}$ pada daun. Dari 36 jenis anak pohon yang diukur, tingkat asimilasi $\mathrm{CO}_{2}$ cukup bervariasi di antara 1,480 - 31,388 $\mu \mathrm{mol} / \mathrm{m}^{2} / \mathrm{s}$, tercatat ada lima jenis yang memiliki tingkat fotosintesis tertinggi, antara lain adalah; Quercus oidocarpa (31,388 $\left.\mu \mathrm{mol} / \mathrm{m}^{2} / \mathrm{s}\right)$, Litsea noronhae $(21,158 \mu \mathrm{mol} /$ $\left.\mathrm{m}^{2} / \mathrm{s}\right)$, Saurauia nudiflora $\left(11,818 \mu \mathrm{mol} / \mathrm{m}^{2} / \mathrm{s}\right)$, Castanopsis argentea $\left(9,333 \mu \mathrm{mol} / \mathrm{m}^{2} / \mathrm{s}\right)$, dan Altingia excelsa $\left(8,770 \mu \mathrm{mol} / \mathrm{m}^{2} / \mathrm{s}\right)$. Sedangkan laju transpirasi berkisar antara $0,790-4,853 \mathrm{~mol} / \mathrm{m}^{2} / \mathrm{s}$, laju transpirasi tertinggi dimiliki oleh jenis Macaranga triloba $\left(4,853 \mathrm{~mol} / \mathrm{m}^{2} / \mathrm{s}\right)$, Sandoricum koetjape $\left(4,253 \mathrm{~mol} / \mathrm{m}^{2} / \mathrm{s}\right)$, Prunus arborea $(4,148$ $\left.\mathrm{mol} / \mathrm{m}^{2} / \mathrm{s}\right)$, Urophyllum corymbosum $(3,908$ $\left.\mathrm{mol} / \mathrm{m}^{2} / \mathrm{s}\right)$ dan Altingia excelsa $(3,815 \mathrm{~mol} /$ 
Tabel 3. Dua puluh jenis pohon yang memiliki nilai biomassa dan kandungan karbon terbesar.

\begin{tabular}{|c|c|c|c|c|c|}
\hline No. & Nama Latin & $\begin{array}{l}\text { LBD } \\
\left(\mathrm{m}^{2} / \mathrm{ha}\right)\end{array}$ & $\begin{array}{c}\text { Biomassa } \\
\text { (kg/berat } \\
\text { kering) }\end{array}$ & Karbon $(\mathrm{Kg})$ & $\begin{array}{l}\text { Jumlah } \\
\text { individu }\end{array}$ \\
\hline 1 & Altingia excelsa & 7.68 & 93825.57 & 46912.78 & 21 \\
\hline 2 & $\begin{array}{l}\text { Blumeodendron } \\
\text { elateriospermum }\end{array}$ & 2.49 & 28823.13 & 14411.57 & 22 \\
\hline 3 & $\begin{array}{l}\text { Castanopsis } \\
\text { acuminatissima }\end{array}$ & 1.81 & 19302.05 & 9651.03 & 12 \\
\hline 4 & Engelhardia serrata & 1.13 & 16084.71 & 8042.35 & 1 \\
\hline 5 & Vernonia arborea & 1.31 & 13727.52 & 6863.76 & 11 \\
\hline 6 & Castanopsis argentea & 1.12 & 11818.81 & 5909.41 & 6 \\
\hline 7 & Dysoxyllum excelsum & 1.08 & 10658.60 & 5329.30 & 12 \\
\hline 8 & Magnolia elegans & 0.97 & 9115.10 & 4557.55 & 10 \\
\hline 9 & Knema cinerea & 0.97 & 8804.40 & 4402.20 & 14 \\
\hline 10 & Castanopsis javanica & 0.72 & 7708.96 & 3854.48 & 5 \\
\hline 11 & Macaranga sp. & 0.70 & 7694.64 & 3847.32 & 3 \\
\hline 12 & Cinnamomum sp. & 0.77 & 7529.65 & 3764.82 & 6 \\
\hline 13 & Elaeocarpus ganitrus & 0.70 & 7203.44 & 3601.72 & 4 \\
\hline 14 & Acer laurinum & 0.55 & 5064.55 & 2532.28 & 7 \\
\hline 15 & Phoebe cf. cuneata & 0.47 & 4637.27 & 2318.64 & 4 \\
\hline 16 & Gordonia excelsa & 0.54 & 4106.56 & 2053.28 & 20 \\
\hline 17 & Tricalysia singularis & 0.50 & 3784.60 & 1892.30 & 17 \\
\hline 18 & Litsea resinosa & 0.41 & 3473.28 & 1736.64 & 7 \\
\hline 19 & $\begin{array}{l}\text { Lithocarpus } \\
\text { pseudomoluccanus }\end{array}$ & 0.27 & 2894.82 & 1447.41 & 1 \\
\hline \multirow[t]{3}{*}{20} & Schima wallichii & 0.26 & 2749.61 & 1374.80 & 2 \\
\hline & 50 jenis lainnya & 4.43 & 35570.34 & 17744.28 & 152 \\
\hline & Jumlah total & 28.89 & 304495.81 & 152247.91 & 337 \\
\hline
\end{tabular}

Keterangan: LBD= Luas Bidang Dasar

$\mathrm{m}^{2} / \mathrm{s}$ ). Tingkat laju fotosintesis dan transpirasi dari jenis lainnya tersaji pada Tabel 4.

Iklim mikro dari masing-masing jenis yang diukur fotosintesis dan transpirasinya adalah; pH tanah berkisar di antara 5,66,6 , kelembaban tanah di antara $53,8-$ $90,3 \%$, suhu udara di antara $23,5-29,4^{\circ} \mathrm{C}$, kelembaban udara di antara $62,5-88,5 \%$ dan intensitas cahaya di antara 585-22892 lux.

Hasil pengukuran di atas sesuai dengan laporan bahwa laju fotosintesis antar jenis tumbuhan berbeda. Tanaman yang tumbuh cepat memiliki laju fotosintesis yang tinggi, tetapi tidak berarti bahwa tumbuhan dengan laju fotosintesis tinggi selalu tumbuh cepat. Tumbuhan dengan laju fotosintesis tinggi mampu menyerap $\mathrm{CO}_{2}$ dalam jumlah lebih banyak dibanding tumbuhan dengan laju fotosintesis rendah. Tumbuhan pohon memiliki kapasitas fotosintesis yang tergolong rendah yakni di antara 2 - 25 $\mu \mathrm{mol} / \mathrm{m}^{2} / \mathrm{s}$ (jenis-jenis pohon di negara 4 musim). Variasi dari kapasitas fotosintesis ini selain dipengaruhi oleh faktor internal 
juga eksternal ${ }^{2,10,11) .}$

Beberapa catatan yang harus diperhatikan dalam pengukuran fotosintesis yakni pertama, kondisi lingkungan tumbuh dan metoda penelitian memiliki pengaruh yang besar terhadap laju asimilasi $\mathrm{CO}_{2}$. Tanaman yang tumbuh pada kondisi in-situ cenderung menunjukkan laju asimilasi $\mathrm{CO}_{2}$ yang lebih tinggi dibandingkan tanaman yang tumbuh pada kondisi lingkungan terkontrol seperti rumah kaca. Karena itu spesifikasi pada kondisi pertumbuhan (seperti ukuran tanaman) dan kondisi lingkungan tumbuh pada saat pengukuran (mikroklimat dan kondisi tanah) dan metoda pengukuran harus disertakan pada hasil pengukuran.

\section{KESIMPULAN}

Bentuk hutan di lokasi penelitian merupakan hutan primer dengan kondisi cukup baik meskipun lokasinya berdekatan dengan perkampungan Citalahab Sentral. Masyarakat di sana benar-benar menjaga kelestarian hutan. Tercatat ada 337 individu pohon (diameter batang di atas $10 \mathrm{~cm}$ ) per hektar dari 71 jenis, 50 marga dan 32 suku. Atingia excelsa tercatat sebagai jenis pohon yang paling dominan. Estimasi biomassa pohon di atas permukaan tanah adalah sebesar 304,5 ton berat kering per hektar dan kandungan karbon 152,3 ton/ha dari Luas Bidang Dasar sebesar $28,89 \mathrm{~m}^{2} /$ ha. Tingkat asimilasi $\mathrm{CO}_{2}$ cukup bervariasi di antara 1,480 - 31,388 $\mu \mathrm{mol} /$

Tabel 4. Laju asimilasi CO2 dan Transpirasi dari masing-masing jenis yang diukur.

\begin{tabular}{|c|l|l|r|r|}
\hline No. & \multicolumn{1}{|c|}{ Nama Latin } & Nama Daerah & $\begin{array}{c}\text { Asimilasi CO2 } \\
(\boldsymbol{\mu m o l / m 2 / s})\end{array}$ & $\begin{array}{c}\text { Transpirasi } \\
(\mathbf{m o l} / \mathbf{m} 2 / \mathbf{s})\end{array}$ \\
\hline 1 & Acer laurinum & Huru bodas & 6.273 & 0.79 \\
\hline 2 & Altingia excelsa & Rasamala & 8.77 & 3.815 \\
\hline 3 & Ardisia zollingeri & Kiajag & 1.745 & 3.005 \\
\hline 4 & $\begin{array}{l}\text { Blumeodendron } \\
\text { elateriospermum }\end{array}$ & Burununggul & 3.308 & 3.315 \\
\hline 5 & $\begin{array}{l}\text { Castanopsis } \\
\text { acuminatissima }\end{array}$ & Kianak & 3.29 & 1.895 \\
\hline 6 & Castanopsis argentea & Saninten & 9.333 & 1.208 \\
\hline 7 & Cinnamomum sp. & Huru buah & 2.928 & 0.98 \\
\hline 8 & Elaeocarpus ganitrus & Ganitri & 1.825 & 3.105 \\
\hline 9 & Eugenia opaca & Kopo & 2.08 & 0.893 \\
\hline 10 & Eugenia polyantha & Salam & 6.335 & 1.013 \\
\hline 11 & Garcinia dioica & Ceri & 5.778 & 1.133 \\
\hline 12 & Gordonia excelsa & Mumuncangan & 3.605 & 3.443 \\
\hline 13 & Knema cinerea & Kimokla & 3.455 & 1.263 \\
\hline 14 & Lithocarpus & Kalimorot & 4.153 & 1.058 \\
\hline 15 & Lithocarpus sp. & Pasang reueuy & 1.503 & 1.21 \\
\hline 16 & Litsea brachystachia & Huru hiris & 3.798 & 3.39 \\
\hline 17 & Litsea mappaceae & Huru hejo & 4.11 & 0.95 \\
\hline 18 & Litsea noronhae & Huru lumlum & 21.158 & 1.53 \\
\hline
\end{tabular}




\begin{tabular}{|c|l|l|c|c|}
\hline No. & \multicolumn{1}{|c|}{ Nama Latin } & Nama Daerah & $\begin{array}{c}\text { Asimilasi CO2 } \\
(\boldsymbol{\mu m o l} / \mathbf{m} \mathbf{2} / \mathbf{s})\end{array}$ & $\begin{array}{c}\text { Transpirasi } \\
(\mathbf{m o l} / \mathbf{m} 2 / \mathbf{s})\end{array}$ \\
\hline 19 & Litsea resinosa & Huru minyak & 6.218 & 3.37 \\
\hline 20 & Macaranga tanarius & Mara bodas & 1.913 & 1.355 \\
\hline 21 & Macaranga triloba & Mara & 2.085 & 4.853 \\
\hline 22 & Magnolia elegans & Maja & 4.19 & 3.622 \\
\hline 23 & Neesia altissima & Bengang & 1.48 & 3.793 \\
\hline 24 & Platea latifolia & Kibonteng & 1.868 & 0.858 \\
\hline 25 & Prunus arborea & Kawoyang & 4.235 & 4.148 \\
\hline 26 & Quercus lineata & Pasang & 4.623 & 1.788 \\
\hline 27 & Quercus oidocarpa & Pasang & 31.388 & 1.473 \\
\hline 28 & Rhodamnia cinerea & Kibeusi & 1.835 & 1.898 \\
\hline 29 & Sandoricum koetjape & Kacapi & 4.148 & 4.253 \\
\hline 30 & Saurauia nudiflora & Kileho & 11.818 & 1.045 \\
\hline 31 & Schima wallichii & Puspa & 5.668 & 1.623 \\
\hline 32 & Symplocos fasciculata & Jirak & 3.99 & 2.983 \\
\hline 33 & Syzygium & Kisireum & 5.628 & 1.258 \\
\hline 34 & Tricalysia singularis & Dawolong & 7.1 & 3.525 \\
\hline 35 & Urophyllum corymbosum & Kokopian & 2.168 & 3.908 \\
\hline 36 & Vernonea arborea & Hamirung & 6.713 & 1.14 \\
\hline
\end{tabular}

$\mathrm{m}^{2} / \mathrm{s}$. Quercus oidocarpa tercatat memiliki tingkat fotosintesis tertinggi, yakni sebesar $31,388 \mu \mathrm{mol} / \mathrm{m}^{2} / \mathrm{s}$. Jenis-jenis lainnya yang juga memiliki fotosintesis tinggi adalah; Litsea noronhae, Saurauia nudiflora, Castanopsis argentea, dan Altingia excelsa. Sedangkan laju transpirasi tertinggi dimiliki oleh jenis Macaranga triloba, Sandoricum koetjape, Prunus arborea, Urophyllum corymbosum dan Altingia excelsa.

\section{DAFTAR PUSTAKA}

1. Rinaldi, D., Syahrial,AH., Dewi, MP., Edy, S., Hary, W., Purwaningsih, Indra, F., Ika, KW., dan Nur, F. 2008. Ekologi Koridor Halimun-Salak, Taman Nasional Gunung Halimun Salak. Gunung Halimun-Salak National Park Project Management. Buku. 37 halaman.
2. Raghavendra AS. 1991. Physiology of Trees. Wiley \& Sons Publ. New York.262p

3. Matsumoto $\mathrm{Y}$, Maruyama $\mathrm{Y}$, Uemura A, Shigenaga $\mathrm{H}$, Okuda S. Harayama $\mathrm{H}$, Kawasaki H, Ang LH, Yap SK. 2003. Gas exchange and turgor maintenance of tropical trees species in Pasoh forest reserve. In: Okuda T, Manokaran N, Matsumoto Y, Niyama K, Thomas SC, Ashton PS (Eds.) Pasho Ecological of Lowland Rain Forest in Southeast Asia. Spreinger - Verlag, Tokyo, pp. 214-250.

4. Takahashi K, Osaki M, Shibuya M, Tamai Y, Saito H, LH, Tuah SJ, Susanto AR, Pidjath C \& Erosa P. 2005. Growth Phenology and Photosinthhetic Traits of tree Species Native to PeatSwamp Foress. Annual Report: Environmental Conservation and Land Use Management of Wetland 
Ecosystem in Southeast Asia. P:68-70.

5. Takahashi K, Shibuya M, Tamai $Y$, Saito H, Swido LH, Tuah SJ,.Susanto AR \& Erosa P. 2006. Morphological and Photosynthetic Characteristics of Shorea selanica and S. balangeran Sapling Planted at Open and Understory Conditions on Peat Soil in Central Kalimantan. Annual Report: Environmental Conservation and Land Use Management of Wetland Ecosystem in Southeast Asia.P:62-68

6. Cox, G.W. 1967. Laboratory Manual Of General Ecology. M.C. Crown, lowa.

7. Greigh-Smith, P. 1964. Quantitative Plant Ecology. Second Edition. Butterworths, London.
8. Brown, S. 1997.Estimating biomass and biomass change of tropical forest, a primer FAO Forestry Paper 134. FAO, Rome.

9. Schmidt, F.H. \& J.H.A. Ferguson. 1951. Rainfall types based on wet and dry period ratios for Indonesia with western New Guinea. Kementerian Perhubungan, Djawatan Meteorologi dan Geofisik. Verhandelingen, No.42.

10. Baker NR (Ed.). 1996. Advanced in Photosynthesis Vol.5: Photosynthesis and the Environment. Kluwer Academic Publishers. 489p

11. Reinhart JC \& Bernard Saugier. 1991. Photosynthesis. In : Raghavendra. A.S. 1991. Physiology of Trees. Wiley \& Sons Publ. New York.262p. 